\title{
Inhibition of Active Substances of Vibrio Parahaemolyticus and its Application Research
}

\author{
Sun Wenke' ${ }^{1}$, Zhang Shuping ${ }^{2, *}$ \\ ${ }^{1}$ University of Shanghai for Science and Technology, College of Science, Yangpu District Military Rd, China \\ ${ }^{2}$ University of Shanghai for Science and Technology, College of Science, Yangpu District Military Rd, China
}

\begin{abstract}
Inhibition of vibrio parahaemolyticus by polyphenol compounds from carageen by plate growth inhibition tested to observe its bacteriostasis effect on V.parahaemolyticus. The test results show that within a certain range, polyphenols from carageen have obvious antibacterial activity against V.parahaemolyticus, the size of antibacterial activity is closely related to polyphenol concentration and molecular mass. The higher the content of polyphenols, the stronger the bacteriostasis it has. It indicates that carageen polyphenol compounds can inhibit V.parahaemolyticus.
\end{abstract}

\section{Introduction}

Vibrio parahaemolyticus is a gram-negative bacterium. It's a naturally pathogen bacteria, also known as V.parahaemolyticus. According to the classification of V.parahaemolyticus, it can be divided into pathogenic and non pathogenic. The pathogenic V.parahaemolyticus can cause gastroenteritis or diarrhea through the intestinal tract, or a septicemia caused by a wound infection. At present, there are more than 10 types of vibrio diseases reported by aquaculture animals, among them, vibrio alginolyticus, V.parahaemolyticus and vibrio vulnificus are the most common diseases ${ }^{[1]}$. Vibrio disease is the major disease of marine cultured animals. It has a wide spread, high morbidity and high mortality characteristic. There have been reports of numerous fish deaths caused by vibrio in Fujian and Zhejiang province $^{[2]}$. Because of the abuse of antibiotics and the protruding bacterial drug resistance, how to inhibit vibrio parahaemolyticus activity has become an important topic. Seaweed polyphenols have strong antibacterial activity and are toxic to other algae, attached organisms and planktonic larvae ${ }^{[3]}$. In recent years, relevant studies at home and abroad have also found that polyphenol compounds in sargassum have strong antitumor activity, antibacterial activity, chemical defense effect $^{[4]}$ and deodorizing activity, etc ${ }^{[5]}$. Fabin Dang ${ }^{[6]}$ etc found that polyphenols in carageen have broad antimicrobial spectrum against vibrio marine, but there are not reports about bacteriostatic activity of V.parahaemolyticus that have yet been reported. We use carageen as the experimental material, V.parahaemolyticus as the tested bacteria, the extraction of polyphenols from carageen by plate growth inhibition method, and we study the inhibitory effect of polyphenols from carageen on V.parahaemolyticus. It is used to provide new ideas and methods for the prevention and treatment of common vibrio diseases in aquaculture.

\section{Experiment}

\subsection{Experimental materials}

\subsubsection{Carageen}

Carageen bought from the Tumen Road vegetable market in Yangpu District, Shanghai. After washing, remove the impurities such as sand on the surface of seaweed. Naturally dry, then freeze and preserve. You need thaw it before you use.

\subsubsection{Bacteria}

V.parahaemolyticus was purchased from Shanghai Lu Wei Technology Co., Ltd.

\subsection{Preparation of reagents}

Folin-Denis: Adding $100 \mathrm{~g} \quad \mathrm{Na}_{2} \mathrm{WO}_{4} \cdot 2 \mathrm{H}_{2} \mathrm{O}, \quad 20 \mathrm{~g}$ phosphomolybdic acid hydrate, $50 \mathrm{ml} \mathrm{H}_{3} \mathrm{PO}_{4}$ to $750 \mathrm{ml}$ water, backflowing $2 \mathrm{~h}$, cooling it then dilute to $1 \mathrm{~L}$.

Preparation of standard liquid for phloroglucinol: $5 \mathrm{~g}$ phloroglucinol is dissolved in $100 \mathrm{ml} 95 \%$ ethanol.

\subsection{Test instrument}

Electrothermal constant temperature dryers (DHG-9053A), Electronic balance (FA2004N), Universal high speed crusher (DE-100g), Heat collector magnetic stirrer with constant temperature (DF-101S), 
Biochemical incubator, etc.

\subsection{Extraction and identification of polyphenols from carageen}

\subsubsection{Extraction of polyphenols from carageen}

First we remove the first surface material, then wash with distilled water to remove second layers of epiphytic organisms, put them in the Electrothermal constant temperature dryers, temperature is set to 100 degree. Wait until the carageen becomes dry matter completely, cryopreserved it. We thaw before using it, dry mass of carageen $10 \mathrm{~g}$, use a Universal high speed crusher to crush it to complete, extracting $2 \mathrm{~h}$ by adding $85 \%$ ethanol to avoid light, the amount of carageen and ethanol is about $1: 2(\mathrm{~g} / \mathrm{ml})$, repeated extraction 3 times, mixing the extract, finally we will obtain the crude extract of carageen polyphenols. And we reduce pressure distillation (emoval of ethanol), dissolve the finished product in water, then wash 2 times with $1 / 2$ volume of ether and chloroform respectively, then reduce pressure distillation, the finished product dissolves in water, finally we will obtain the essence of the extract ${ }^{[7,8,9]}$, put in the freezer for cryopreservation.

\subsubsection{Determination of the content of polyphenols extract from carageen}

Brown algae polyphenols are a kind of phenolic compounds with basic structure units of phloroglucinol. We use AOAC standard analysis method, using Folin-Denis ${ }^{[10]}$ reagent to form a blue complex with polyphenols under alkaline conditions, colorimetric analysis at $\lambda=709 \mathrm{~nm}$, standard curve drawing with phloroglucinol ${ }^{[11]}$ as standard, and then the relative content of carageen polyphenols was calculated. Because polyphenols extract contained mannito ${ }^{[12]}$, mannitol and $\mathrm{NaCI}$ were used as controls.

$\mathrm{X}$ is absorbance and $\mathrm{Y}$ is concentration, data analysis by using Matlab, the relationship between the content of polyphenols and the absorbance is that: $y=61.8201 x+20.2077$, the results show that the content of polyphenols in this experiment is $411.0289 \mu \mathrm{g} / \mathrm{ml}$.

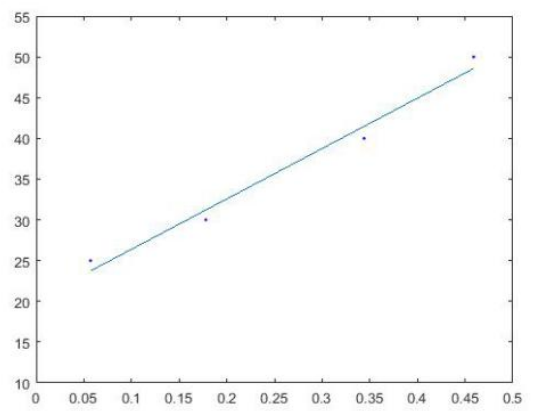

Fig. 1. Standard curve of carageen polyphenols

\subsubsection{Preparation of culture medium}

Nutrient agar medium: peptone $10 \mathrm{~g} / \mathrm{L}, \mathrm{NaCI} 5 \mathrm{~g} / \mathrm{L}$, agar powder $15 \mathrm{~g} / \mathrm{L}$, beef powder $3 \mathrm{~g} / \mathrm{L}$, weighing the medium $33 \mathrm{~g}$, adding distilled water $1000 \mathrm{ml}$, heat dissolving and put into the flask, sterilizing and standby by 121 degree $15 \mathrm{~min}, \mathrm{ph} 7.6 \sim 7.8^{[9]}$.

\subsubsection{Preparation of polyphenols from carageen}

The polyphenol extract was melted at room temperature before the experiment and we number the EP tube, we separately configure the concentration of $50 \mu \mathrm{g} / \mathrm{ml}$, $100 \mu \mathrm{g} / \mathrm{ml}, 200 \mu \mathrm{g} / \mathrm{ml}, 400 \mu \mathrm{g} / \mathrm{ml}, 800 \mu \mathrm{g} / \mathrm{ml}, 1200 \mu \mathrm{g} / \mathrm{ml}$, $1600 \mu \mathrm{g} / \mathrm{ml}, 2000 \mu \mathrm{g} / \mathrm{ml}$.

\subsubsection{Preparation of bacterial plate}

Take the activated bacteria, make a certain density of bacteria suspension. Take $0.2 \mathrm{ml}$ of the bacterial suspension and pour into the aseptic plate, and then immediately pour into the medium $15 \mathrm{ml}$ with high temperature sterilization and cooling to 45 degree, let the bacterial liquid mix well with the medium and ready for use.

\subsection{Determination method of bacteriostasis activity}

Use aseptic glass pipette to punch $2.5 \mathrm{~mm}$ hole in bacteria plate, add a sample of $10 \mu \mathrm{l}$ per hole, each sample is added to a hole, and about $15 \mathrm{~mm}$ from the side of the culture plate, $5 \% \mathrm{NaCI}$ and $3 \%$ mannitol were used as the control group. The remaining 4 holes were put into different concentrations of carageen polyphenols extract, the concentrations were $50 \mu \mathrm{g} / \mathrm{ml}, 100 \mu \mathrm{g} / \mathrm{ml}, 200 \mu \mathrm{g} / \mathrm{ml}$, $400 \mu \mathrm{g} / \mathrm{ml}$, and so on. Then the culture plate was put into 36 degree incubator to cultivate $24 \mathrm{~h}$, measure the diameter of the bacteriostasis circle (deducted the diameter of the aperture), mean value of bacteriostasis.

\section{Results and discussion}

\subsection{Morphology of VP}

Electron microscopy revealed that it is round, curved, rod-shaped, filamentous, and has no spores, as shown in Fig. 2. A size of about $210 \times 180 \mathrm{~nm}$, as shown in Fig. 3.

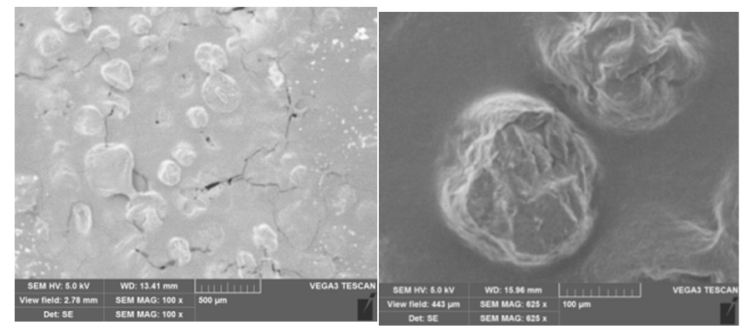

Fig. 2. and Fig. 3. Electron microscopy of VP

3.2 Bacteriostatic effect and analysis of different concentrations of polyphenols 
Table 1. Polyphenols content of carageen and diameter

\begin{tabular}{|c|l|l|l|l|}
\hline $\begin{array}{c}\text { Oolyphenols content } \\
(\mu \mathrm{g} / \mathrm{ml})\end{array}$ & $\begin{array}{l}5 \% \\
\mathrm{NaCI}\end{array}$ & $\begin{array}{l}3 \% \\
\text { mannitol }\end{array}$ & 50 & 100 \\
\hline $\begin{array}{c}\text { Diameter of } \\
\text { bacteriostasis } \\
\text { circle(mm) }\end{array}$ & 0 & 0 & 0 & 0.5 \\
\cline { 2 - 5 } & 0 & 0 & 0 & 0.5 \\
\cline { 2 - 5 } & 0 & 0 & 0 & 0.5 \\
\cline { 2 - 5 } & 0 & 0 & 0 & 0.7 \\
\cline { 2 - 5 } & 0 & 0 & 0 & 0.9 \\
\hline Mean value $(\mathrm{mm})$ & 0 & 0 & 0 & 0.62 \\
\hline
\end{tabular}

\begin{tabular}{|l|l|l|l|l|l|}
\hline 200 & 400 & 800 & 1200 & 1600 & 2000 \\
\hline 0.6 & 1.0 & 1.5 & 1.7 & 1.9 & 2.4 \\
\hline 0.6 & 1.5 & 2.0 & 2.2 & 2.2 & 2.5 \\
\hline 0.7 & 1.0 & 1.5 & 1.7 & 2.0 & 2.3 \\
\hline 1.0 & 1.5 & 1.6 & 1.7 & 2.1 & 2.5 \\
\hline 1.4 & 1.9 & 2.1 & 2.4 & 2.6 & 3.0 \\
\hline 0.86 & 1.38 & 1.74 & 1.94 & 2.16 & 2.54 \\
\hline
\end{tabular}

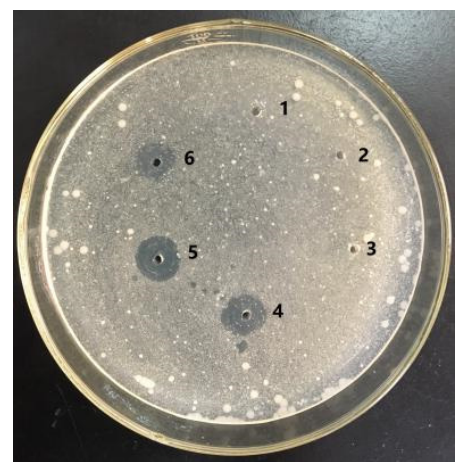

Fig. 4. Inhibitory effect of carageen polyphenols on V.parahaemolyticus

1. $5 \% \mathrm{NaCl}$ 2. $3 \%$ Mannitol 3. $50 \mu \mathrm{g} / \mathrm{ml} 4.100 \mu \mathrm{g} / \mathrm{ml} 5.200 \mu \mathrm{g} / \mathrm{ml}$ 6. $400 \mu \mathrm{g} / \mathrm{ml}$

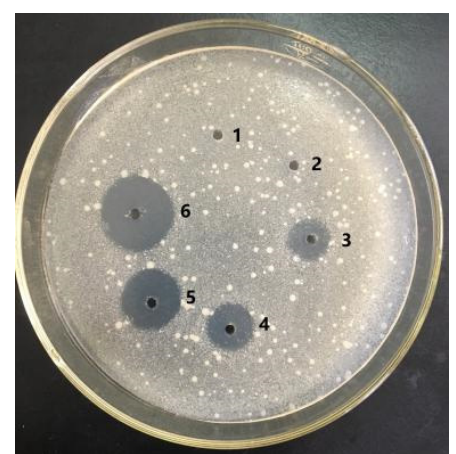

Fig. 5. Inhibitory effect of carageen polyphenols on V.parahaemolyticus

1. $5 \% \mathrm{NaCI}$ 2. 3\%Mannitol 3. $800 \mu \mathrm{g} / \mathrm{ml} 4.1200 \mu \mathrm{g} / \mathrm{ml} 5$. $1600 \mu \mathrm{g} / \mathrm{ml} 6.2000 \mu \mathrm{g} / \mathrm{ml}$

The mean single factor analysis of the results of V.parahaemolyticus from the same source of carageen polyphenols, the results obtained (after removal of glass pipette)are converted to data, analysis of variance using SPSS 19, The results show that the antibacterial effect of polyphenol from the same source on V.parahaemolyticus was significantly different. Carageen polyphenols: $\mathrm{F}_{12,21}=6.059, \mathrm{P}=0.000$, Because $\mathrm{P}<0.05$, the antibacterial ability is related to polyphenol content, as shown in Table 1 , the higher the polyphenol content, the stronger the bacteriostatic ability.

\subsection{Estimated marginal mean}

The polyphenol content test showed that when the polyphenol content was low, carageen polyphenols had little difference in bacteriostatic ability of V.parahaemolyticus, but with the increase of polyphenol concentration, the difference became more significant. The results of simple effect test, as shown in Fig. 6.

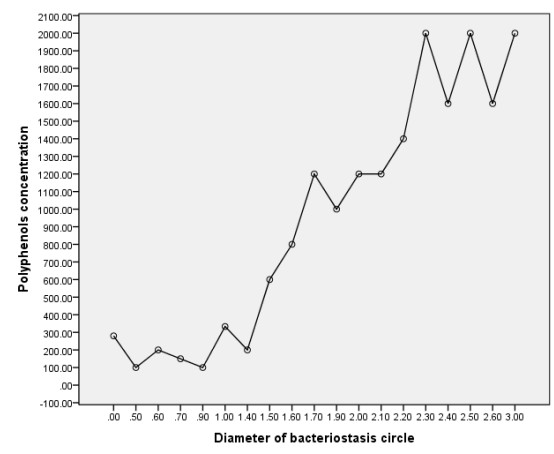

Fig. 6. Estimate marginal mean contour

\section{Conclusion}

On the whole, the results in this study demonstrated that the inhibitory effect of carageen on V.parahaemolyticus was determined by plate method. It was found that the inhibition of carageen polyphenols is closely related to its concentration, when the concentration of polyphenol decreased to a certain concentration, the inhibitory effect disappeared. Bacterial disease is one of the most common and serious diseases in aquaculture. Once the outbreak of infection can occur in a short time, a large number of fish and shrimp died, resulting in huge losses to the aquaculture industry. The results showed that the polyphenol of carageen has potential application value in the prevention and treatment of V.parahaemolyticus.

\section{Reference}

1. Conover J T, Sieburth J M. Effect of Sargassum distribution on its Epibiota and antibacterial activity[J]. Botanica Martin, 1964, 6(2): 147-157.

2. Chao L. Physiological activities of polyphenols from two species of brown algae[D]. Qingdao: Qingdao University, 2005.

3. Anne A, Boettcher, Nancy M. Rple of polyphenolic molecular size in reduction of asssimilation efficiency in xiphister mucosus[J]. Ecology, 1993, 74(3): 891-903. 
4. Qi G, Yuxi W, Bangzhong Y, etc. Study on bacteriostasis activity of polyphenols fractionated components of caudal alga[J]. Progress in fishery science, 2010, 31(1): 117-121.

5. Fabin D, Wei W, Gengchao C, etc. Bacteriostasis of several seaweed polyphenols on fish pathogenic bacteria[J]. Fisheries Science, 2012, 31(8): 500-501.

6. Bulet P, Cociancich S, Dimarcq J, et al. Isolation from a coleopteran insect of a novel inducible antibacterial peptide and of new members of the insect defensin family[J]. $J$ Biol Chem, 1991, 266(36): 24 520-24 524.

7. Shicui Z, Xiao F. Principles and applications of Marine Biotechnology[M]. Beijing: Ocean Publishing House, 1998:10-11.

8. Yuxi W, Shuguang Y. Antioxidant activity of two ethanol extracts from brown algae[J]. Marine Science, 2002, 26(9): 49-51.

9. Chao L, Shuguang Y, Daosen G, etc. Antimicrobial activity of alginate polyphenols from Sargassum[J]. Marine Science, 2006, 30(3): 94-97.

10. Minghou J. Seaweed Chemistry[M]. Beijing: Science Press, 2004: 628-629.

11. Yanghua Y, Binghua J. Modern Marine Pharmacology[M]. Beijing: Science Press, 2006: 296-297.

12. Zhenbing Z, Tengfei D, Shichang W, etc. Extraction, isolation, purification and antibacterial activity test of polyphenols from Sargassum[J]. Journal Of Anhui Agricultural Sciences, 2009, 37(17): 7809-7811. 